\title{
The Dynamics of Brand-Driven Quality Improvement Decision-Making in Multi-Small-Supplier Agri-Food Supply Chain: The Case of China
}

\author{
Jing $\mathrm{Mu}^{1, *}$, Jing $\mathrm{Li}^{2},{\text { Yaze } \mathrm{Li}^{2}}^{2}$ and Chao Liu ${ }^{1}$ \\ 1 Food Supply Chain Research Institute, Tianjin University of Science and Technology, Tianjing 300457, China; \\ liuchao@tust.edu.cn \\ 2 School of Economics and Management, Tianjin University of Science and Technology, Tianjing 300457, China; \\ 15222617580@163.com (J.L.); 15547095426@163.com (Y.L.) \\ * Correspondence: mujing@tust.edu.cn
}

check for updates

Citation: Mu, J.; Li, J.; Li, Y.; Liu, C. The Dynamics of Brand-Driven Quality Improvement DecisionMaking in Multi-Small-Supplier Agri-Food Supply Chain: The Case of China. Sustainability 2021, 13, 10815. https://doi.org/10.3390/su131910815

Academic Editor: Riccardo Testa

Received: 24 August 2021

Accepted: 25 September 2021

Published: 29 September 2021

Publisher's Note: MDPI stays neutral with regard to jurisdictional claims in published maps and institutional affiliations.

Copyright: (c) 2021 by the authors. Licensee MDPI, Basel, Switzerland. This article is an open access article distributed under the terms and conditions of the Creative Commons Attribution (CC BY) license (https:// creativecommons.org/licenses/by/ $4.0 /)$.

\begin{abstract}
This paper develops a system dynamics framework for the closed-loop agri-food brand supply chain (AFBSC) with multiple small farmer suppliers and one core brand manufacturer, and investigates the influences of various factors including brand effort, quality elasticity, price elasticity, revenue sharing, and the number of suppliers on the system behavior. The results show: (i) food quality is determined by all farmer suppliers, who might choose hitchhiking with the prisoner's dilemma game in a decentralized decision-making mode; (ii) brand effort to improve brand value for food quality is mainly made by the core brand manufacturer, who presents a goal-seeking system dynamics (SD) manner with oscillation behavior around the expected quality of consumers; (iii) whether farmer suppliers or brand manufacturers, the centralized decision-making mode is more useful for them to increase revenue than the decentralized one; furthermore, the shared centralized decisionmaking mode is most useful for them to obtain more revenue, and the brand manufacturer is still the biggest beneficiary.
\end{abstract}

Keywords: brand-driven quality improvement; multi-small supplier; agri-food supply chain; SD

\section{Introduction}

Food quality and safety are some of the main concerns of consumers and health agencies around the world [1]. Food quality and safety issues have profound influences on the design of the agri-food supply chain. The agri-food supply chain has different characteristics from other supply chains, which is mainly reflected by factors like food quality, safety, and freshness within a limited time, and is difficult to manage [2]. Due to poor management and inefficiency in the food supply chain, as of 2021, 1.3 billion tons of food will be wasted due to decay and deterioration, equivalent to USD 1 trillion [3]. On the other hand, the National Grain and Material Reserve Bureau survey found that 35 million tons of food is wasted every year in China, which is close to $6 \%$ of its total food output. Among them, due to poor management and low efficiency of the food supply chain, as of 2021, 70 billion catties of food was wasted due to food processing and transportation [4]. The consumption trends of fresh vegetables demonstrate that shelf life and food safety are relevant factors in orienting consumer choices [5]. Thus, the quality management of the agri-food supply chain is of paramount importance. Past literature [6-8] has used mixed-integer linear programming theory or Stackelberg game theory to develop analytical dynamic models for production and distribution planning and centralized and decentralized decision-making, incorporating various reward schemes to improve food quality of the entire supply chain and facilitate the supplier's quality improvement efforts. For any agriculture brand products, the brand value promotion of agriculture products in the agri-food supply chain led by the core manufacturer also plays a significant role in improving food quality and safety [9-12]. Hence it is necessary to incorporate brand-driven 
decision-making into the agri-food supply chain to improve food quality and safety with high efficiency.

Past literature regarding brand-driven strategy in improving food quality and safety has primarily focused on customer perceived value, brand value, and consumer satisfaction. For instance, there is a strong relationship in customer's perceived value toward a brand and loyalty, while the brand economic values seem to be more important than emotional and social values in determining customer satisfaction. [13]. Brand value contains both tangible and intangible elements, these intangible values make one product different from its competitors and develop a differentiated brand, influencing consumer preferences and enhancing customer satisfaction levels $[14,15]$. The brand value is created by different actors throughout the supply chain and the magnitude of the overall added value is ultimately decided by the end-consumer's willingness to pay [16-18]. Obviously, enhancing the brand value of agriculture products is an important way to promote the quality improvement of agriculture products, and food quality mainly depends on customers' perception of food quality.

The above literature offers a valuable contribution; however, the quality improvement of the agri-food supply chain will address safety and quality of both the products and processes in various sectors [19]. Some studies have adopted a penalty contract controlling the supplier's quality failures [20-23], while other studies have adopted an incentive contract or economic incentive schemes to manage the quality of supply chain in which the supplier is principally responsible for overall product quality [24-26]. In addition, the perishability and short shelf life of agriculture products create uncertainty for the buyer with respect to product quality, safety, and supply reliability, which leads to vulnerability in coordination among stakeholders in the brand value chain. Traditional methodologies cannot solve these problems, so we employ the system dynamics (SD) methodology, well known and proven in strategic decision-making, as the major modeling and analysis tool in this research [27-30].

System dynamics (SD) is a structural theory of social systems and can be fruitfully used in the operation management context to explain a variety of phenomena, and the SD models are minor or midrange content theories of social settings [31]. The SD methodology is very suitable for studying the long-term strategic decision behavior of agri-food supply chains. Minegishi and Thiel have perfectly captured the use of SD as a strategic tool and use SD to improve the understanding of the complex logistic behavior of an integrated food industry, presenting a generic model and providing practical simulation results applied to the field of poultry production and processing [32]. Guma et al. apply the SD approach to aid stakeholders understanding the feedback mechanisms among complexities of food security and providing effective decision as global resource consumption continues to grow [33]. Olafsdottir et al. describe the learning loop that involves in developing a causal loop diagram (CLD) for supply chain analysis [34]. Teimoury et al. have developed the SD model to solve different kinds of problems in the food supply chains, in which they clearly outline the different strategies adopted to manage the operations in the upstream and downstream of the supply chains [35].

This paper focuses on brand-driven decision-making to improve food quality and safety in the Chinese agri-food supply chain. Two backgrounds of this scenario are described below: (i) the Chinese agri-food supply chain generally takes the core agricultural brand manufacturer (dragon head enterprise) as a management core for product control, information sharing, and supply chain finance [36,37]. However, the relationships between farmers and brand manufacturers have various weaknesses such as vulnerability in coordination and farmers' difficulty in obtaining added value [38], and the cooperation among participants in the Chinese agri-food supply chain is still unstable [37]. (ii) The No. 1 document of China's central government in 2019 once again has stressed the importance of improving food quality, in fact, the fundamental solution to food safety problems is that all participants in the food supply chain make efforts to invest in quality [37,39]. Meanwhile, 
the road of quality agriculture was put forward emphasizing brand building strategy throughout the entire agricultural industry chain [40].

Food quality and safety of agriculture brand products have become common issues in China owing to continuous scandal cases. There have been numerous reports in the news [41-43] about excessive pesticide residues in agricultural products such as fruits and vegetables. As far as the Chinese agri-food brand supply chain (AFBSC) is concerned, it is characterized by multiple small farm suppliers, and there are no long-term contracts between farmer suppliers and the core brand manufacturer. Even if the core brand manufacturer makes effort to enhance brand value of agriculture products, low-quality supply of agriculture raw materials may also lead to a decline in food quality. Thus, the core brand manufacturer needs to stimulate farmer suppliers' brand awareness to improve high-quality supply of raw materials. However, there is a paradox: farm suppliers who determine food quality cannot directly benefit from quality improvement, whereas the core brand manufacturer who benefits from quality improvement cannot directly determine food quality [44], which will bring many food quality and safety issues worth studying.

Based on the Chinese multi-small-supplier AFBSC, the purpose of this paper is threefold: (i) to explore the reasons for low-quality supply of agriculture raw materials; (ii) to analyze the SD mechanism of brand-driven quality improvement decision-making that meets the consumers' perceptions and expectations of brand value and food products; (iii) to compare three different strategies for quality improvement and to propose the optimal decision-making based on the SD manner. The brand-driven revenue sharing decision-making for quality improvement requires the establishment of stable long-term contracts between the core brand manufacturer and farmer suppliers, by which farmer suppliers will provide high-quality agriculture raw materials and the brand manufacturer will make efforts to brand building for food quality improvement. Hence the SD methodology is used in modeling and simulation to analyze the long-term decision-making for multi-small-supplier AFBSC in China.

The rest of the paper is organized as follows. The next section discusses the closed-loop structure of multi-small-supplier AFBSC, and the hitchhiking phenomenon of multiple farmer suppliers leading to low-quality supply of agriculture raw materials, as well as the goal-seeking SD manner of the core manufacturer's brand-driven decision-making for quality improvement. In the subsequent sections, three decision-making modes of decentralized, centralized, and shared and centralized are compared through mathematical analysis models, the shared centralized AFBSC is quantified to improve food quality, and managerial implications are derived. This paper concludes with a discussion on the summary of insights from this research and the scope of further research.

\section{Background}

\subsection{A Simple Chinese Case}

This paper will take Tianjin Quebao Supermarket Corporation (TQSC) as a case, which has its own AFBSC and is known for chives in the northern of China. As the source of AFBSC, the planting scale of TQSC raw chives is not large enough, lots of raw chives depend on purchasing chives from other farmers. In 2018, TQSC's total vegetable transaction volume was 16.98 million tons. According to an estimation of 1 percent of the total, the chives transaction volume is 16,980 tons. However, the annual output of chives from TQSC's own planting base is only 1575 tons, it is clear that lots of chives need to be purchased from other farmers. On the other hand, each farmer has a small planting scale with area of about 1 to 4 acres, which can produce 5 to 20 tons of chives. It is roughly estimated that the number of TQSC's farmer suppliers will reach nearly 10,000 , which is forming an AFBSC with multiple small farmer suppliers and one brand manufacturer, but there is no long-term contract between farmers and brand manufacturer, as shown in Figure 1. 


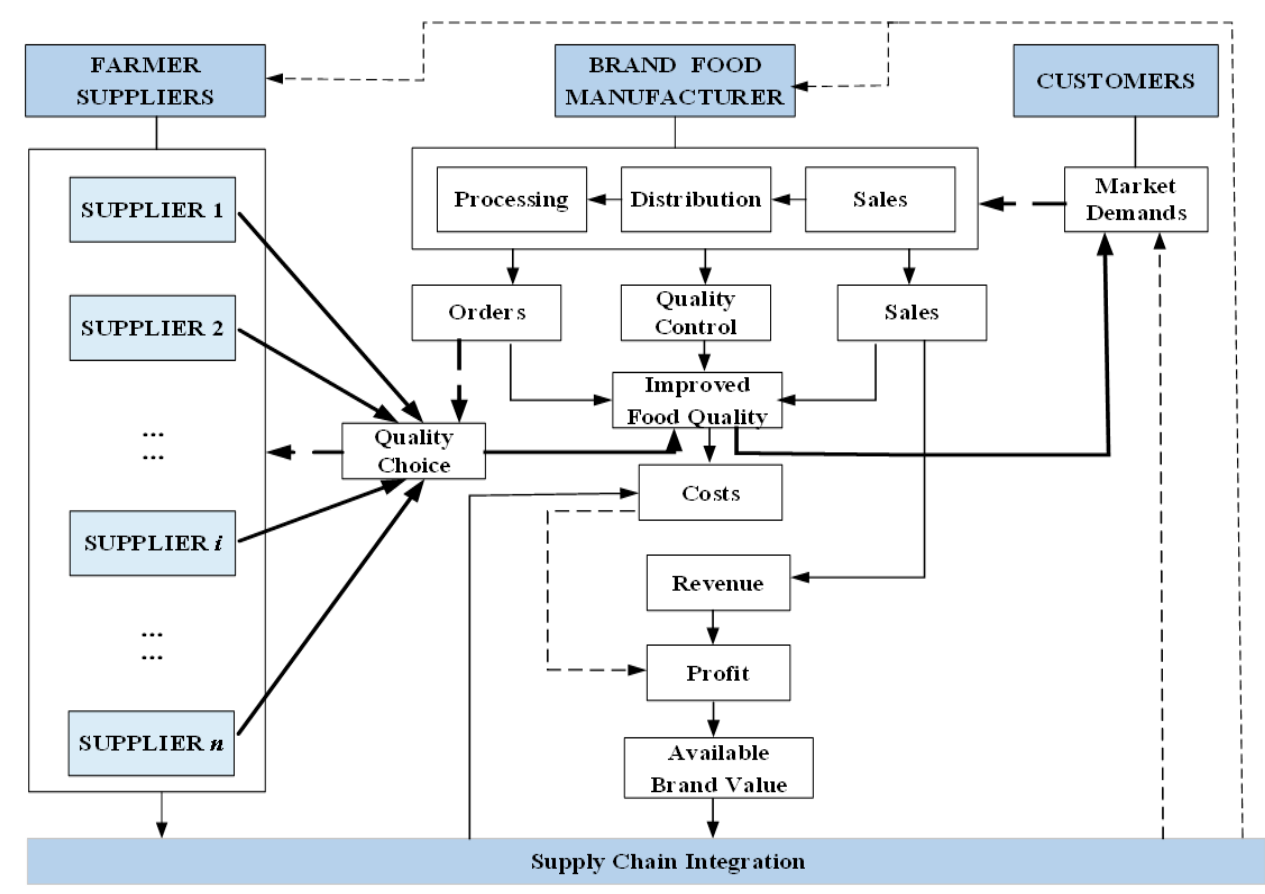

Figure 1. The closed-loop frame of agri-food brand supply chain (AFBSC) (solid lines denote direct relationship, dashed lines denote inverse relationship).

In the AFBSC shown in Figure 1, the food brand manufacturer is a core actor, who is the builder, owner, and beneficiary of the brand, and the biggest victim too; the upstream participants are $\mathrm{N}$ farmer suppliers, who are independent decision makers. For the whole AFBSC, higher quality leads to lower costs and higher profits, thereby increasing available brand value. Furthermore, during the AFBSC operation, there is a relatively loose cooperative relationship between the core food brand manufacturer and its upstream suppliers. As a core actor, the brand food manufacturer purchases the raw materials from suppliers, processing and transforming them into the finished food product, and finally shipping them to a retailer for end-customers purchase by the name of store brand or private label products. As usual, the food quality mainly depends on the quality of raw materials, and the food products of high quality made from raw materials of high quality will have a positive impact on the end-consumer demands, the result of which is that the suppliers determine the quality of food products, and the high-quality brand products will generate high profit.

\subsection{Assumptions}

Based on the above, the following assumptions are proposed: (i) the end-consumer market demand is known and affected by food quality; (ii) single brand manufacturer as core actor and $\mathrm{N}$ small farmer suppliers are considered; (iii) a single brand item is considered; (iv) raw materials to finished goods factor is 1:1; (v) raw materials are equally distributed among $\mathrm{N}$ farmer suppliers; (vi) food quality mainly depends on the quality of raw materials from farmer suppliers; (vii) consumers' desired food quality determines the brand value of food products; (viii) the purchasing price of raw materials is determined by the core actor manufacturer and is constant.

\section{SD General Principles and Knowledge}

\subsection{Model, Structure, and Behavior}

System dynamics models are symbolic models consisting of a combination of diagrams, graphs, and equations, which are thus descriptive models. The structure of a system can be defined as the totality of the relationships that exist between system variables, which operates over time so as to produce the dynamic behavior patterns of the system 
variables. It is said that the structure creates the behavior. The structure of a system dynamics model is a set of differential and/or difference equations, while the dynamic behavior of the model is obtained by simulation. Alternatively, we typically represent the structure by a stock-flow diagram and associated simulation equations. These simulation runs are also called sensitivity tests, as they try to assess how much the output behavior changes as a result of changes in selected parameters, inputs, initial conditions, function shapes, or other structural changes [45].

\subsection{Causal Relations, Not Mere Statistical Correlations}

The very purpose of system dynamics study requires that the model consist of causal relations, not mere statistical correlations. It is possible to generate excellent short-term forecasts by non-causal correlational models, but impossible to understand and control dynamic problems [46].

\subsection{Time Delay and Oscillating Structures}

There are time delays involved between causes and effects and between actions and reactions. Time delays often play an important role in the dynamics of systems. There are two general categories of time delays in system dynamics: material delays and information delays. Material delays exist on material stock-flow chains, information delays may mean a "delayed effect" of a variable on another one. Delay structures are not direct causal formulations, they are behavioral approximations to the outputs of many cause-effect interactions. Having delays in structures are potential sources of oscillatory behavior. A very typical managerial application of delays is in the context of the standard goalseeking structure $[46,47]$.

\section{SD Behavior of Farmer Suppliers and Brand Manufacturer}

\subsection{Hitchhiking Behavior of Multiple Farmer Suppliers}

In the AFBSC of Figure 1, farmer suppliers have short-term contracts with the food brand manufacturer instead of long-term contracts, forming a decentralized supply chain. Figure 2 depicts the multi-small supplier hitchhiking behavior for farmer suppliers to select the quality of raw materials through the stock-flow diagram. As shown in Figure 2, among $\mathrm{N}$ suppliers in the decentralized supply chain there are two groups: suppliers choosing high-quality (HQ) raw materials and suppliers choosing low-quality (LQ) raw materials, these two groups all will provide raw materials for the same brand manufacturer, independently making decision and bumping into one another in the service of the manufacturer. During the operation of the AFBSC, the manufacturer will purchase raw materials from farmer suppliers at a price lower than the market price, and there is a price game between the suppliers of choosing HQ raw materials and the ones of choosing LQ raw materials. In fact, the farmer suppliers cannot directly get the higher returns from the HQ raw materials they provide, because that the total raw materials required by the brand manufacturer are equally distributed among $\mathrm{N}$ suppliers, each supplier will almost get the same returns as other suppliers, whether providing HQ raw materials or LQ ones. As a result, some suppliers would like to choose hitchhiking, furthermore, as the number of suppliers increases, the quality of raw materials will become lower and lower.

Vensim 8.0.9 is used to simulate the hitchhiking SD behavior of the multi-small supplier described by the stock-flow diagram in Figure 2, in which there is a reinforcing feedback loop. The simulation results are shown in Figure 3. Starting with the game between HQ suppliers and LQ suppliers, and then multiplying by the transition fraction, the simulation describes the suppliers' dynamic behavior of providing raw materials from high-quality to low-quality. The supplier change rate of providing raw materials from $H Q$ to LQ indicates the quality of raw materials changes from high to low as the number of suppliers increases or changes in different $\mathrm{N}$ values (e.g., $\mathrm{N}=200,400$, or 600). Similarly, as shown in Figure 3, with the increase in the number of suppliers, more and more farmer suppliers provide low-quality raw materials for food brand manufacturers, and the quality 
of raw materials is rapidly changing from high to low. Hence it is shown that the raw materials quality is not determined by a single supplier, but by all suppliers. As the number of suppliers increases, their selection behavior will fall into a prisoner's dilemma. The parameters, variables and equations in this section are listed in Appendix A.

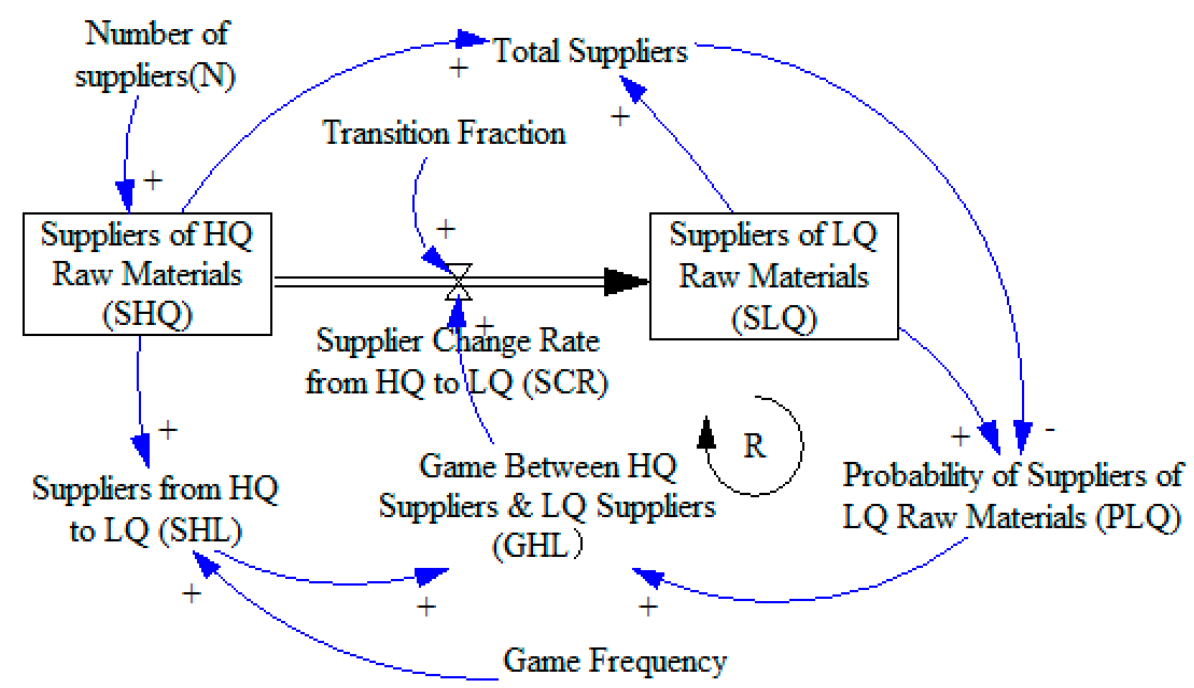

Figure 2. The stock-flow diagram of multi-small suppliers choosing hitchhiking.

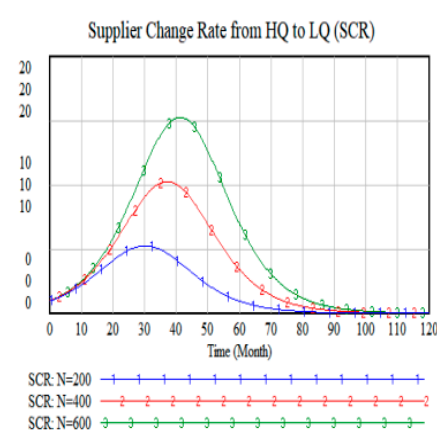

(a)

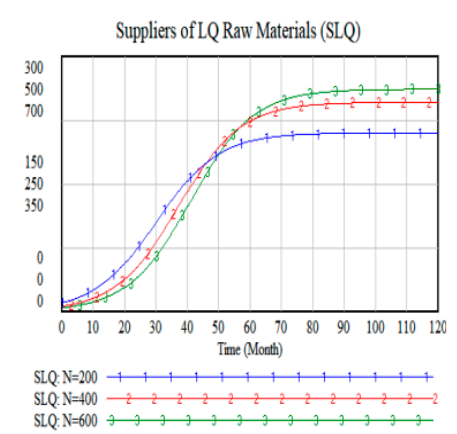

(b)

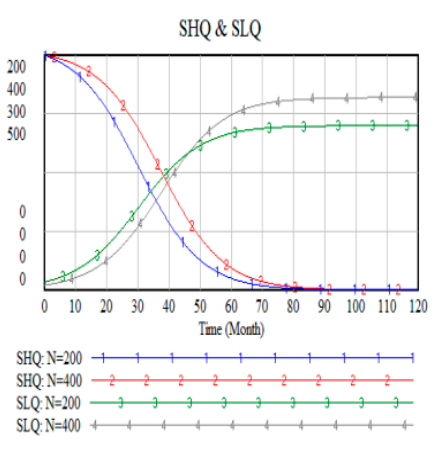

(c)

Figure 3. The behavior of suppliers with the increase of $\mathrm{N}$ : (a) supplier change rate of selection from $H Q$ to $L Q$ is getting faster and faster; (b) more suppliers choosing providing $L Q$ raw materials; (c) comparison of suppliers' selection changes from HQ to LQ.

\subsection{Brand-Driven Quality Improvement Decision-Making Behavior of Manufacturer}

Brand value is actually co-created by brand manufacturers and consumers, enhancing the brand value of agriculture products is an important way to improve the quality of agriculture products. Figure 4 depicts the stock-flow diagram of brand-driven quality improvement decision-making for brand manufacturers to improve agri-food quality through brand improvement effort and improving brand value of agriculture products and increasing the perceived quality of consumers. In this stock-flow diagram, there are two reinforcing feedback loops and two balancing feedback loops, and the bigger balancing loop is IVM-IVE-QPR-PQC-QIR-IQD-FQA-IQC-EBE-EC-BER-BEM-BI-VIR-IVM, in which there is a third-order information delay from IVM to PQC to IQM.

As shown in Figure 4, the improved brand value of manufacturer is denoted by $V(t)$, which increases as the brand improvement effort $E(t)$ and price difference increase, as shown in Formula (1):

$$
\dot{V}(t)=\lambda E(t)-\delta V(t)+\zeta\left(P_{S}-P_{r}\right), t \in[0, T]
$$


where $\lambda>0$ refers to brand effort efficiency and $\delta>0$ refers to brand value decaying fraction. The additive term $\zeta\left(P_{s}-P_{r}\right)$ stands for brand snob effect, where $P_{s}$ is a selling price, and $P_{r}$ is a reference price $[48,49]$. If the selling price is greater than the reference price, then the brand value will increase; otherwise, if the selling price is too low, the brand is undervalued. Therefore, $\zeta>0$ is called the price sensitivity coefficient toward the brand value.

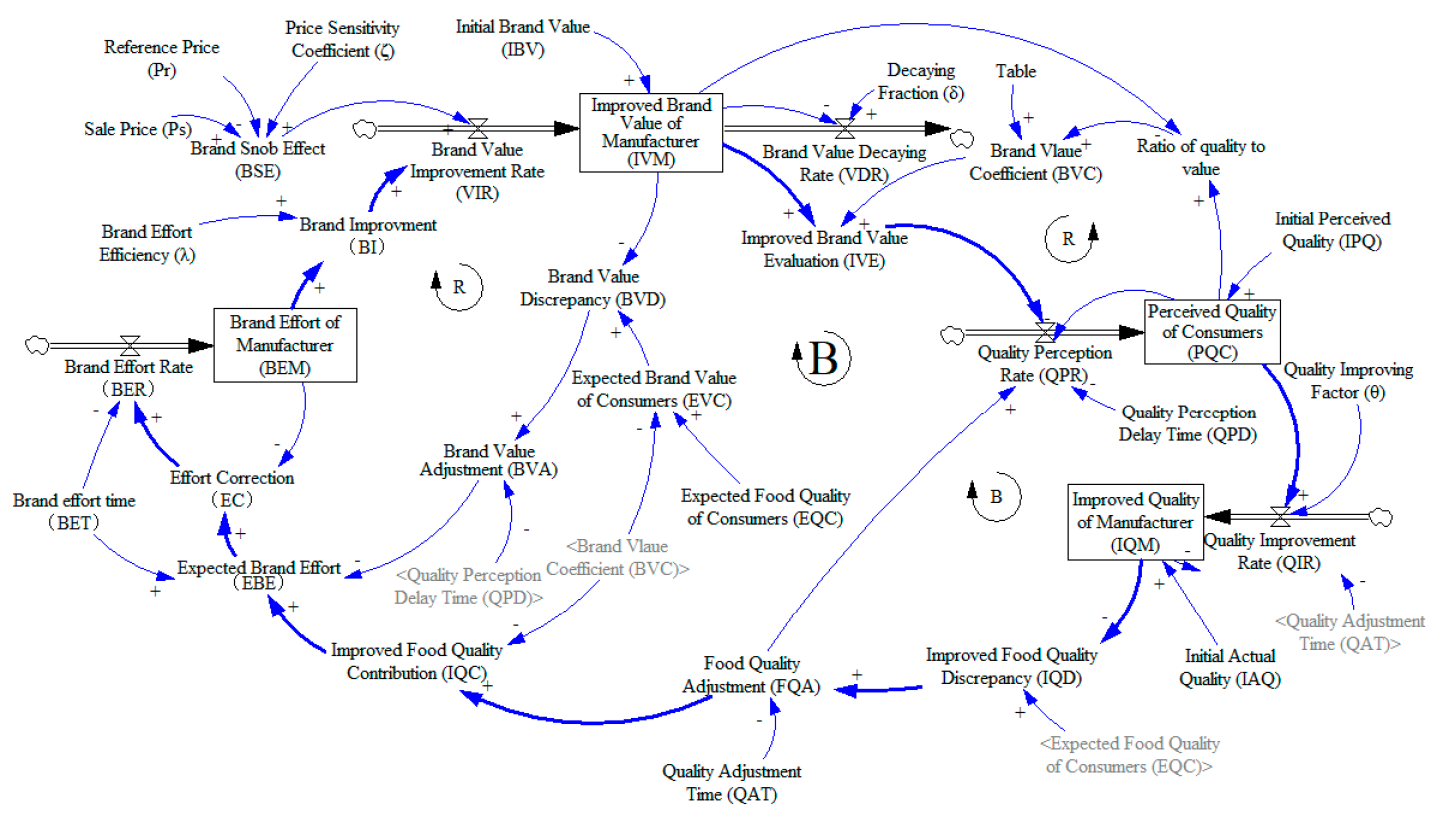

Figure 4. The stock-flow diagram of brand-driven quality improvement of manufacturers.

The consumers' perception of brand value and food quality, that is perceived quality of consumers, always lags behind the improved brand value of manufacturers. In short words, there is a time lag between the consumers "get" and the manufacturer "give". The Figure 4 is the stock-flow diagram for the manufacturer to improve food quality. Figure 5 depicts the dynamic behavior of the model.

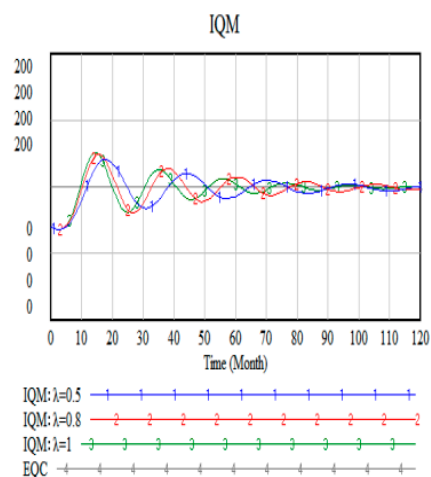

(a)

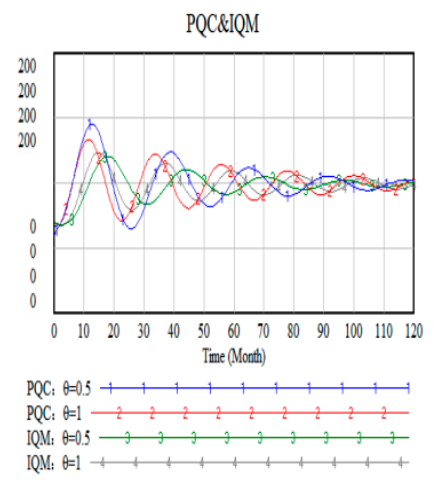

(b)

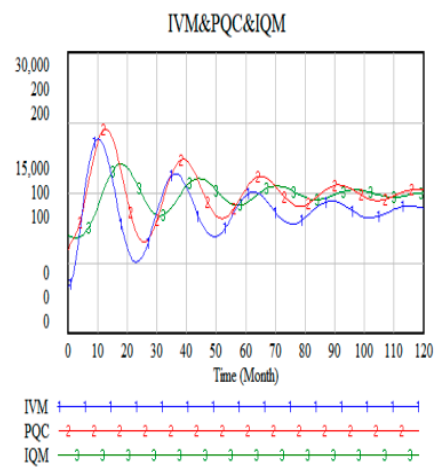

(c)

Figure 5. The behavior of manufacturers: (a) product quality is getting closer and closer to consumer expectations with brand improvement efforts; (b) product quality is delayed after perceived quality and finally approaches consumer expectations; (c) product quality is delayed by the third-order after brand improvement and finally approaches consumer expectations.

As mentioned above, the brand value of the AFBSC depends on the end-consumer's willingness to pay and is positively correlated with consumer demand. The result is that the higher the consumer demand, the stronger the purchasing power, the greater the market demand, and the greater the profit of the whole supply chain, especially the greater the 
profit of the core actor manufacturer. Thus, the core actor manufacturer prefers to organize production meeting the consumer demand. On the other hand, the consumer expectations are varying with the consumer perception of brand value or food product quality, whereas the consumer perception determines their expectations. In order to make consumers more satisfied, the manufacturer will make greater efforts to increase their investment in food brand building in order to improve food quality and increase brand value. As shown in Figure $5 \mathrm{a}$, as the $\lambda$ value increases (e.g., $\lambda=0.5,0.8$, or 1 ) when $\theta=0.5$, that is, as the brand effort efficiency increases, the harder the manufacturer makes effort, the faster the food quality will improve. Meanwhile, Figure $5 \mathrm{~b}$ illustrates the development trends of the PQC and the IQM with the increasing of the $\theta$ value (e.g., $\theta=0.5$ or $\theta=1$ ) when $\lambda=0.5$. As the simulation time goes on and the $\theta$ value increases from 0.5 to 1 , the PQC and the IQM are changing in the same direction and reaching consumer satisfaction faster and faster. Figure $5 \mathrm{c}$ depicts the oscillation behavior of third-order information delay from IVM to PQC to IQM. The parameters, variables and equations in this section are listed in Appendix B.

According to the SD model and simulation analysis conducted in this section, it can be seen that as the manufacturer makes greater effort or investment in food brand building and food quality improvement, the consumer perception and recognition of food brands and quality are gradually improved and the consumer demand and purchasing power are expanded, which will bring more revenues to the core actor manufacturer even the whole food supply chain.

\section{Comparison of Three Decision-Making Modes for Quality Improvement}

In China, many farmer suppliers only sign short-term contracts with brand manufacturers, most of which are carried out through hawkers, and there are no long-term contracts. For instance, TQSC has a lot of farmer suppliers who provide them with raw chives, but most of farmer suppliers are scattered and have only temporary deals with them. According to Figure 3, the more farmer suppliers and the worse the quality of raw materials, in order to improve food quality, the core actor manufacturer has to change his decision-making from the decentralized to the centralized, and meanwhile share the brand revenue of supply chain with the upstream farmer suppliers. An AFBSC integrated revenue model of decentralized and centralized and shared decision-making is developed in Figure 6 in the SD manner, and the mathematical models of decentralized, centralized, and shared decision-making are given below.

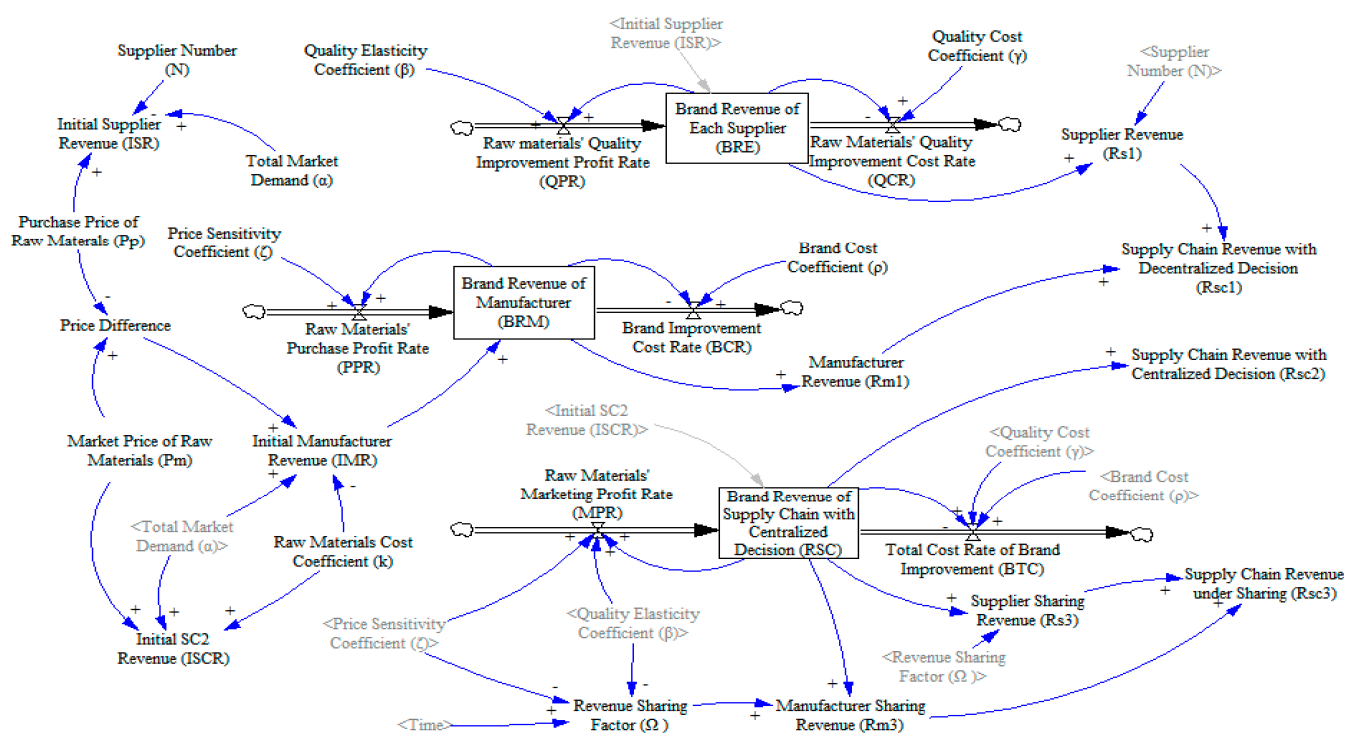

Figure 6. The stock-flow diagram of integrated revenue model with decentralized, centralized, and shared decision-making. 


\subsection{Mathematical Model of Decentralized Decision-Making}

The decentralized approach, a low level of centralization, characterizes supply chains where each participant independently manages its own decisions. For example, the hitchhiking behavior of the multiple small suppliers described in Figure 2 to Figure 3 is the result of decentralized decision-making in the AFBSC. Brand manufacturer and farmer suppliers make independent decisions, there is no uniform requirement for quality and price. As the number of farmer suppliers increases, more of them want to obtain higher profits at lower prices, so more choices are considered to provide low-quality raw materials. As a result, the overall quality of food products is determined by the worst quality of raw materials and getting worse and worse, the consumers' perceived brand value of food products is becoming less and less, and the total brand revenue of supply chain is getting lower and lower. The model is described as follows.

The brand revenue of each supplier is represented by $R_{s i}(t)$, which increases with the increase in the raw materials' quality $Q(t)$, and decreases with the increase in the cost of improving the raw materials' quality, as shown in the following differential equation:

$$
\dot{R}_{s i}(t)=1 / N(\alpha+\beta Q(t))-\gamma R_{s i}(t)
$$

where $\alpha>0$ is the total market demand for raw materials, $\beta>0$ is the quality elasticity coefficient of raw materials, $\gamma>0$ is the cost coefficient of the raw materials' quality improvement, and $N>1$ is the total number of suppliers.

Furthermore, the brand revenue of manufacturer is represented by $R_{m}(t)$, which mainly depends on the raw material procurement profit $P(t)$ and the brand improvement cost, as shown in the following differential equation:

$$
R_{m}(t)=\left(P_{m}-P_{p}\right)(\alpha+\zeta P(t))-\rho R_{m}(t)
$$

where $P_{m}>0$ and $P_{p}>0$ respectively stand for the market price and purchase price of raw materials, and $\rho>0$ is the brand cost coefficient.

In summary, for the decentralized decision, the brand revenue of supply chain represented by $R_{s c 1}$ is as follows:

$$
R_{s c 1}=R_{s 1}+R_{m 1}=N R_{s i}+R_{m}
$$

where $R_{s 1}$ and $R_{m 1}$ respectively stand for the brand revenue of farmer suppliers and manufacturer under the decentralized decision-making of the supply chain, $R_{s i}$ and $R_{m}$ respectively, are calculated by Equations (2) and (3).

\subsection{Mathematical Model of Centralized Decision-Making}

For the centralized decision, the product quality and brand value perceived by consumers are not determined by a single supplier, but by all suppliers. Thus, all the farmer suppliers may be considered as a whole, the whole revenue of the supply chain represented by $R_{s c 2}(t)$ is calculated according to the following formula:

$$
\dot{R}_{s c 2}(t)=P_{m}(\alpha+\beta \zeta M(t))-\gamma \theta R_{s c 2}(t)
$$

where $M(t)$ represents the purchase profit of the supply chain. However, due to the regional, seasonal, and structural surplus characteristics of vegetable products with the large price fluctuations, many vegetable farmers are more mobile and only sign short-term contracts with brand manufacturers or no contracts, and supplier management is even more difficult. For example, the TQSC always has to replace chives suppliers in different seasons. Therefore, the centralized decision-making mode is a better choice. 


\subsection{Mathematical Analysis of Shared Decision-Making}

On the other hand, food quality mainly depends on the quality of raw materials provided by farmer suppliers. Furthermore, high quality plays a huge role in brand promotion. Therefore, in order to promote the brand value or brand reputation, the brand manufacturer will have to encourage suppliers to invest costs in improving raw material quality by sharing benefit from brand improvement and promotion. In other words, the core actor manufacturer should share supply chain revenue with the upstream farmer suppliers. $\Omega$ represents the revenue sharing factor which is related to $\zeta$ and $\beta$. The revenue sharing shares of farmer suppliers and brand manufacturers are respectively represented by $R_{s 3}$ and $R_{m 3}$, and the supply chain revenue is represented by $R_{s c 3}$. The calculation formula is as follows:

$$
\Omega=\zeta /(\zeta+\beta), R_{m 3}=(1+\Omega) R_{s c 2}, R_{s 3}=(2-\Omega) R_{s c 2}, R_{s c 3}=R_{m 3}+R_{s 3}
$$

Considering the Formulas (2)-(6), the following conditions should be met:

$$
R_{m 3} \geq R_{m 1} ; R_{s 3} \geq R_{s 1} ; R_{m 3}+R_{3}=3 R_{s c 2} ; R_{s c 3} \geq R_{s c 2} \geq R_{s c 1}
$$

\section{The Optimal Decision-Making for Quality Improvement}

Based on the stock-flow diagram in Figure 6 and the mathematical model described by Formulas (2)-(7), the SD simulation is depicted in Figure 7 to Figure 8.

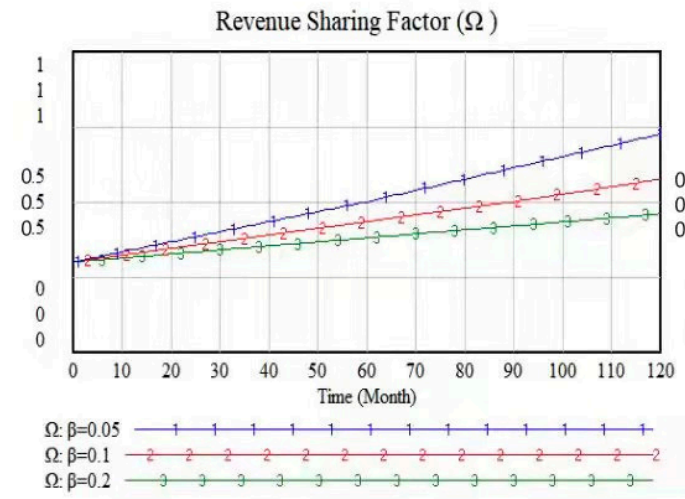

(a)

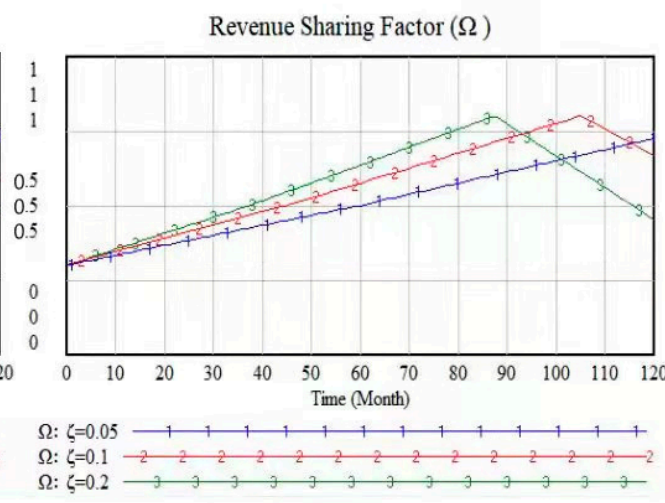

(b)

Figure 7. The change of $\Omega$ : (a) the $\Omega$ becomes smaller and smaller with the increase of $\beta$; (b) the $\Omega$ rises first and then falls with the increase of $\zeta$.

As shown in Figure 7, It is seen that the revenue sharing factor $\Omega$ value gradually becomes lower and lower with the increase of the quality elasticity coefficient $\beta$ value (Figure $7 \mathrm{a}$, e.g., $\beta=0.05,0.1,0.2$ ). On the other hand, the $\Omega$ rises first and then falls as the price sensitivity coefficient $\zeta$ value changes, and the faster the $\Omega$ value declines as the greater the $\zeta$ becomes (Figure $7 \mathrm{~b}$, e.g., $\zeta=0.05,0.1,0.2$ ). It is shown that with the quality improvement of raw materials provided by farmer suppliers, the manufacturer will share more revenues with suppliers; similarly, with the price increase of raw materials provided by farmer suppliers, the manufacturer will also share more revenues with suppliers.

As shown in Figure 8a, whether brand manufacturer or farmer suppliers, the revenue from decentralized decision-making is always less than the revenue from centralized sharing decision-making; furthermore, the revenue of the centralized and shared decision is always larger and growing faster than that of the decentralized decision or the centralized. This shows that the centralized decision is very effective in improving the efficiency of the AFBSC. Meanwhile, considering the special characteristics of vegetables, in order to improve the quality of raw materials and thus the quality of food products, the total brand revenue of the centralized decision-making supply chain is shared by farmer suppliers and brand manufacturers. In addition, whether farmer suppliers or brand manufacturers, 
the shared revenue of the centralized decision-making is higher than that of the decentralized decision-making, meanwhile, brand manufacturer's revenues are always larger than farmer suppliers' revenues (Figure 8a, e.g., Rm1 and Rs1 or Rm3 and Rs3). Among the three decisions, the SC revenue of shared decision-making is the largest, followed by centralized decision-making, and the SC revenue of decentralized decision-making is the smallest (Figure 8b, e.g., Rsc1, Rsc2, and Rsc3). The parameters, variables and equations in this section are listed in Appendix C.

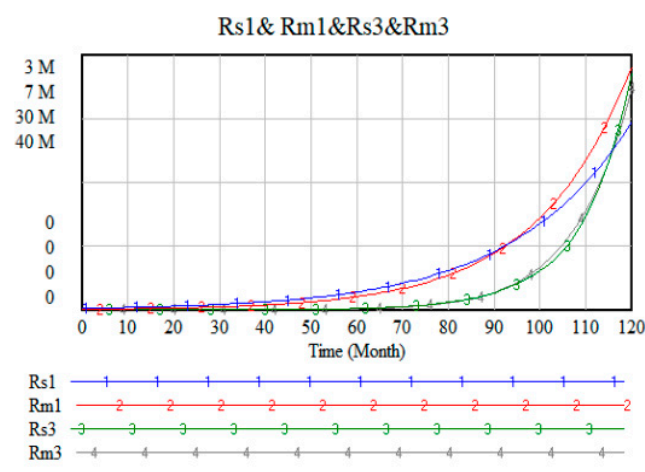

(a)

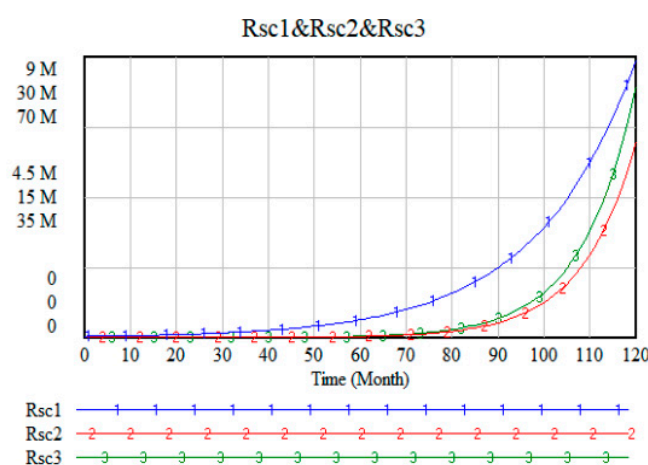

(b)

Figure 8. The brand revenue comparison: (a) whether farmer supplier or brand manufacturers, the revenue of shared and centralized decision-making is always greater than that of decentralized decision-making or centralized, and the manufacturer's revenue is always greater than that of suppliers; (b) for the AFBSC, the shared and centralized decision-making's revenue is the largest, followed by the centralized decision-making, and the decentralized decision-making's revenue is the least.

Overall, it is further explained that the AFBSC's centralized and shared decision driven by brand revenue share not only motivates suppliers to improve the raw materials' quality, but also that the brand manufacturer is still the biggest beneficiary.

\section{Discussion}

By considering the influence of multiple factors, this paper establishes a system dynamics framework for a closed-loop agri-food brand supply chain with multiple smallholder suppliers, one core brand manufacturer, and then proposes a supply chain quality management decision, hoping providing theoretical guidance in the practical activities of controlling food quality under the predicament of supplier supply.

The main theoretical contributions and findings of the article are as follows:

(1) Multiple farmer suppliers have hitchhiking behaviors, they present a goal-seeking system dynamics (SD) manner with oscillatory behavior. As the number of suppliers increases, their selection behavior will fall into a prisoner's dilemma in a decentralized decision-making mode.

(2) There is a third-order information delay from IVM and PQC to IQM. The present model provides a basic foundation upon which some various extensions could be built. The third-order materials delay structure may be introduced to depict the dynamic behavior of the growth of the agri-product professional association supported by the finical supply chain in the SD manner. The sustainable development of food brand supply chain deserves further exploration.

(3) The centralized decision-making mode is more useful for suppliers and core manufacturers to increase revenue than the decentralized one, in addition, the shared centralized decision-making mode is the most useful.

The main practical contributions of the article are as follows:

(1) Through the SD simulation of actual problems, the article can guide more food enterprises to get bigger and stronger and become brand enterprises to ensure food safety. 
(2) In terms of China's rural reality, food brand enterprises should be encouraged to develop large-scale farmer suppliers (e.g., family farming) to improve their supply chains through redesigning organizational structure. For instance, an agri-product professional association should be introduced as a bridge between food brand enterprises and farmers, by which the food brand enterprise makes a long-term contract with farmers and motivates farmers to invest in the large-scale family planting through the finical supply chain.

The present model also suffers from several limitations. First, the model may be more accessible, but some parameters and their value ranges need to be adjusted to make them more realistic. There is undoubtedly potential improvement by expanding application cases to other brand food products, e.g., brand fruit, brand milks, etc. The second limitation is that the definition of the initial value in the level variable needs further adjustment, for example, adjusting the initial value of improved quality, brand value, or perceived quality, etc. The third limitation concerns the policy analysis in the AFBSC's centralized and shared decision-making, which the quality improvement decision-making needs to be proposed through sensitivity analysis. In addition, although taking China as an example to study the decision-making problem of agricultural product supply chain, the model, and simulation of this study can be extended to other countries.

\section{Conclusions}

As for AFBSC, the core brand manufacturer can take the decentralized or centralized decision-making mode. However, if choosing the decentralized decision-making mode, since there are no long-term contracts, many small stakeholder suppliers will not get effective revenue from the investment in high quality of raw materials. As a result, more farmer suppliers might choose hitchhiking and providing LQ raw materials, thereby reducing the product quality of the whole AFBSC. Relatively, the centralized decision-making mode is a better alternative solution.

The brand value is created by different actors throughout the supply chain and the magnitude of the overall added value is ultimately decided by the end-consumer's willingness to pay. On the one hand, it will take some time for the brand manufacturer to improve the quality to be perceived by consumers, and the model of brand-driven quality improvement of manufacturers presents the goal-seeking SD structure and the oscillation behavior around the EQC and finally approaching it. On the other hand, it takes time for consumers' quality perception to go from low to high, caused by the information delay. That is, the behavior of PQC lags behind IVM, it takes time for consumers to adjust their PQC according to IQM in the process of searching information and making decisions, which leads to a change in IVM. So, the delay in the implementation of the decision-making process constitutes an oscillatory behavior from IVM and PQC to IQM. Therefore, brand manufacturers should strive to improve brand value and product quality to meet consumers' perceptions and expectations of quality.

The centralized decision-making mode is more useful to increase the AFBSC's revenue than the decentralized one, but due to small suppliers' mobile and uncertain characteristics like the TQSC's Chives suppliers, the centralized decision-making mode is less feasible and not effective for improving the quality of raw materials and food products. Therefore, as the revenue sharing factor $\Omega$ is introduced that is related to price factor $\zeta$, and quality factor $\beta$, the shared and centralized decision-making mode can provide an effective solution to improve quality and increase revenue of the whole food supply chain. As shown in Figure 8, compared with the decentralized or centralized decision-making mode, the shared centralized decision-making mode will make brand manufacturer and farmer suppliers get more revenues, and the brand manufacturer increases revenue faster than the farmer suppliers and is still the biggest beneficiary.

Regarding future research, sustainability has become an important driver in defining business strategies, especially the promotion of sustainable marketing in the food industry [50], therefore, the sustainable development strategy of the food brand supply chain 
will be further explored in the future. In addition, this article will improve the accuracy and authenticity of the data and value ranges in the model, and extend the application cases to other branded foods, such as branded fruits and branded milk, which undoubtedly have potential improvements. Lastly, this article will adjust and optimize the model structure, and expand the research scope from the decision-making of agricultural supply chains in China as an example to the applicability of decision-making in other countries' agricultural supply chains.

Author Contributions: Conceptualization, methodology, formal analysis, investigation, J.M.; software, J.L. and Y.L.; writing - original draft preparation, J.M.; writing—review and editing, J.M., J.L., Y.L. and C.L. All authors have read and agreed to the published version of the manuscript.

Funding: This research was funded by the National Social Science Foundation of China "Research on innovation system of food safety social co-governance from the perspective of brand value chain", grant number (17BGL017).

Institutional Review Board Statement: Not applicable.

Informed Consent Statement: Not applicable.

Data Availability Statement: Not applicable.

Conflicts of Interest: The authors declare no conflict of interest.

Appendix A. Model 1-Hitchhiking Behavior of Multiple Farmer Suppliers

Table A1. Parameters.

\begin{tabular}{cccc}
\hline Parameters & Description & Value & Units \\
\hline Initial time & Simulation start time & 0 & month \\
Final time & Simulation end time & 120 & month \\
Game Frequency & $\begin{array}{c}\text { Frequency of suppliers changing from } \\
\text { high-quality to low-quality } \\
\text { Number of farmer suppliers }\end{array}$ & 10 & $1 /$ month \\
N & $\begin{array}{c}\text { Proportion of suppliers transiting from } \\
\text { high-quality to low-quality }\end{array}$ & 0.01 & person \\
Transition Fraction & \begin{tabular}{c} 
dmnl \\
\hline
\end{tabular}
\end{tabular}

Table A2. Variables.

\begin{tabular}{clc}
\hline Variable Name & \multicolumn{1}{c}{ Description } & Variable Type \\
\hline SHQ & Number of suppliers that provide high-quality raw materials & \\
SLQ & Number of suppliers that provide low-quality raw materials & Stock \\
SCR & Rate of suppliers changing from high-quality to low-quality & Flow \\
\hline
\end{tabular}

Table A3. Equations.

\begin{tabular}{ccc}
\hline Variable Name & Equation & Variable Type \\
\hline SHQ & INTEG $(-$ SCR, N) & Stock \\
SLQ & INTEG $($ SCR, 10) & Flow \\
SCR & GHL $\times$ Transition Fraction & \\
Total Suppliers & SHQ + SLQ & \\
GHL & HLQ $\times$ PLQ & Auxiliary \\
PLQ & SLQ $/$ Total Suppliers & \\
SHL & SHQ $\times$ Game Frequency & \\
\hline
\end{tabular}


Appendix B. Model 2-Brand-Driven Quality Improvement Decision-Making Behavior of Manufacturer

Table A4. Parameters.

\begin{tabular}{cccc}
\hline Parameters & Description & Value & Units \\
\hline Initial time & Simulation start time & 0 & month \\
Final time & Simulation end time & 120 & month \\
BET & Brand effort time & 3 & month \\
EQC & Expected food quality of consumers & 100 & points \\
IBV & Initial brand value & 5000 & yuan \\
IPQ & Initial perceived quality & 60 & points \\
IAQ & Initial actual quality & 70 & points \\
Pr & Reference price of brand food & 45 & yuan $/$ box \\
Ps & Sale price of brand food & 50 & yuan $/$ box \\
QAT & Quality adjustment time & 4 & month \\
QPD & Quality perception delay time & 6 & month \\
$\delta$ & Brand value decaying fraction of manufacturer & 0.01 & $1 /$ month \\
$\zeta$ & Price sensitivity coefficient & 0.5 & dmnl \\
$\lambda$ & Brand effort efficiency & $0.5,0.8$, or 1 & $1 /$ month \\
$\theta$ & Food quality improving factor & 0.5 or1 & $1 /$ month \\
\hline
\end{tabular}

Table A5. Variables.

\begin{tabular}{ccc}
\hline Variable Name & Description & Variable Type \\
\hline IVM & Accumulation of improved brand value of manufacturer & \\
IQM & Accumulation of improved food quality of manufacturer & Stock \\
PQC & Accumulation of perceived food quality of consumers & \\
BEM & Accumulation of brand effort of manufacturer & \\
BER & Change rate of brand effort for manufacturer & \\
VIR & Change rate of brand value improvement of manufacturer & \\
VDR & Change rate of brand value decaying of manufacturer & Flow \\
QPR & Change rate of food quality perception of consumers & \\
QIR & Change rate of food quality improvement of manufacturer & \\
\hline
\end{tabular}

Table A6. Equations.

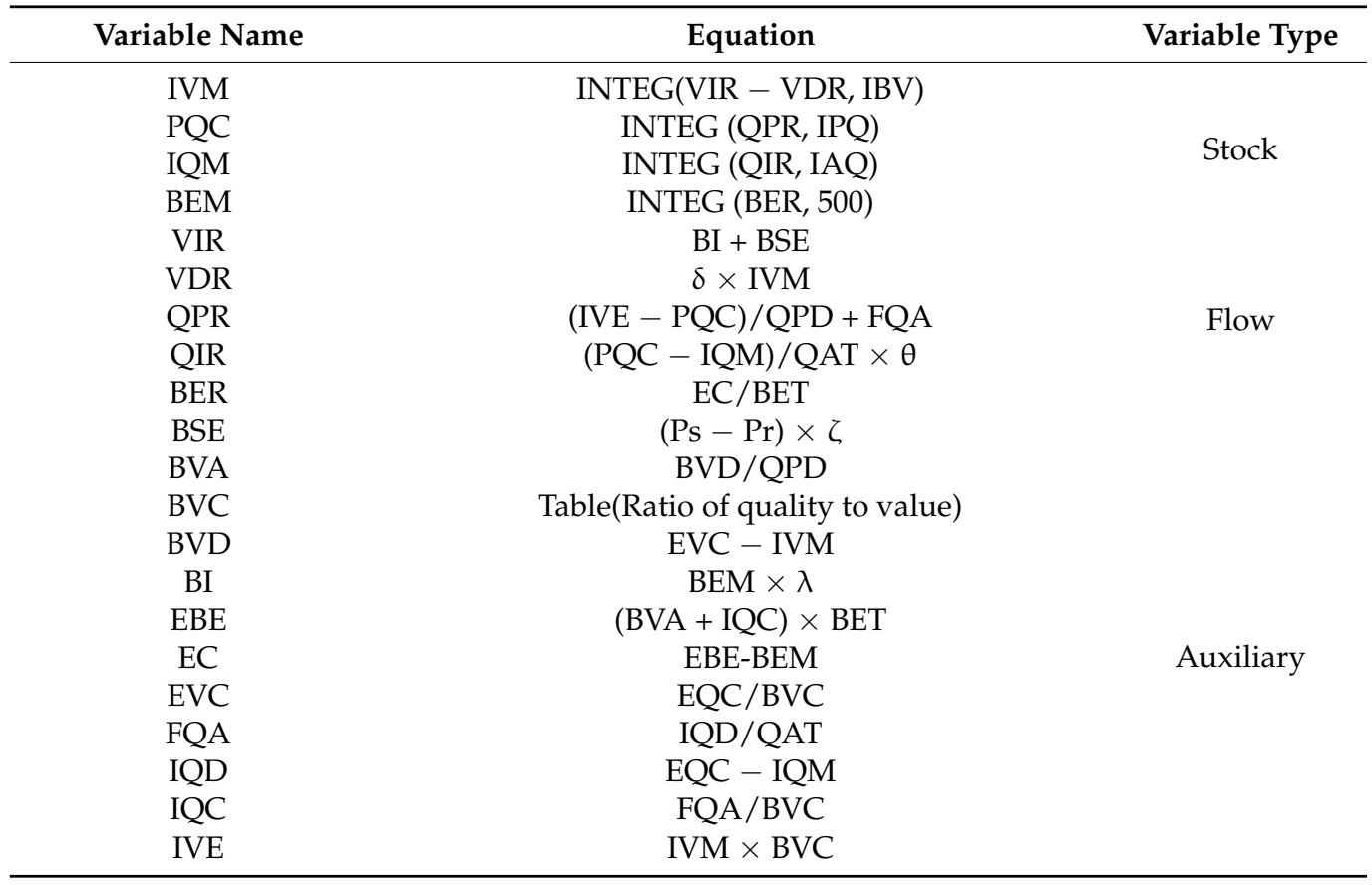


Table A9. Cont.

\begin{tabular}{ccc}
\hline Variable Name & Equation & Variable Type \\
\hline Rsc1 & Rm1 + Rs1 & \\
Rsc2 & RSC & \\
Rsc3 & Rm3 + Rs3 & \\
\hline
\end{tabular}

\section{References}

1. Ruiz-Capillas, C.; Herrero, A. Impact of biogenic amines on food quality and safety. Foods 2019, 8, 62. [CrossRef]

2. Scalia, G.L.; Settanni, L.; Micale, R.; Enea, M. Predictive shelf life model based on RF technology for improving the management of food supply chain: A case study. Int. J. RF Technol. 2016, 7, 31-42. [CrossRef]

3. Yang, D.X.; Han, J.; Wang, Q.; Tian, Y.; Liu, Y. International experience in reducing food loss and combating food waste and its enlightenment to China. World Agric. 2021, 6, 62-71.

4. Li, Y.Z.; Li, M.D. Analysis of media governance practices in mainstream media to stop food waste in 2020. J. Lover 2021, 8, 89-91.

5. Zhong, R.; Xu, X. Food supply chain management: Systems, implementations, and future research. Ind. Manag. Data Syst. 2017, 117, 2085-2114. [CrossRef]

6. Baselice, A.; Colantuoni, F.; Lass, D.; Nardone, G.; Stasi, A. Trends in EU consumers' attitude towards fresh-cut fruit and vegetables. Food Qual. Prefer. 2017, 59, 87-96. [CrossRef]

7. Rong, A.; Akkerman, R.; Grunow, M. An optimization approach for managing fresh food quality throughout the supply chain. Int. J. Prod. Econ. 2011, 131, 421-429. [CrossRef]

8. He, Y.; Xu, Q.Y.; Xu, B.; Wu, P.K. Supply chain coordination in quality improvement with reference effects. J. Oper. Res. Soc. 2016, 67, 1158-1168. [CrossRef]

9. Yoo, S.H.; Cheong, T. Quality improvement incentive strategies in a supply chain. Transp. Res. Part E 2018, 114, 331-342. [CrossRef]

10. Saak, A. Collective reputation, social norms, and participation. Am. J. Agric. Econ. 2012, 94, 763-785. [CrossRef]

11. Moschini, G.C.; Menapace, L.; Pick, D. Geographical indications and the competitive provision of quality in agricultural markets. Am. J. Agric. Econ. 2008, 90, 794-812. [CrossRef]

12. Tselempis, D.; Karipidis, P.; Tzimas, D.; Karypidou, I. Factors that impact farmers' engagement in local food brand development. EuroMed J. Bus. 2019, 15, 86-101. [CrossRef]

13. Dardak, R.A.; Quoquab, F. Consumer perceived value, satisfaction and loyalty on agriculture brand. Econ. Technol. Manag. Rev. 2010, 5, 79-87.

14. Davcik, N.S.; Silva, R.V.D.; Hair, J.F. Towards a unified theory of brand equity: Conceptualizations, taxonomy and avenues for future research. J. Prod. Brand Manag. 2015, 24, 3-17. [CrossRef]

15. Manning, L.; Smith, R. Providing authenticated food: An opportunity driven framework for small food companies to engage consumers and guarantee the integrity of the food supply chain. Int. J. Entrep. Innov. 2015, 16, 97-110.

16. Sánchez, J.; Callarisa, L.; Rodríguez, R.M.; Moliner, M.A. Perceived value of the purchase of a tourism product. Tour. Manag. 2006, 27, 394-409. [CrossRef]

17. Babin, B.J.; James, K. A brief retrospective and introspective on value. Eur. Bus. Rev. 2010, 22, 471-478. [CrossRef]

18. Trienekens, J.H. Agricultural value chains in developing countries: A framework for analysis. Int. Food Agribus. Manag. Rev. 2011, $14,51-82$.

19. Manning, L.; Baines, R.N. Globalisation. A study of the poultry meat supply chain. Br. Food J. 2004, 106, 819-836. [CrossRef]

20. Chao, G.H.; Iravani, S.M.R.; Savaskan, R.C. Quality Improvement Incentives and Product Recall Cost Sharing Contracts. Manag. Sci. 2009, 55, 1122-1138. [CrossRef]

21. Hsieh, C.C.; Liu, Y.T. Quality investment and inspection policy in a supplier-manufacturer supply chain. Eur. J. Oper. Res. 2010, 202, 717-729. [CrossRef]

22. Dong, Y.; Xu, K.F.; Xu, Y.; Wan, X. Quality management in multi-level supply chains with outsourced manufacturing. Prod. Oper. Manag. 2016, 25, 290-305. [CrossRef]

23. Gao, C.Y.; Cheng, T.C.E.; Shen, H.C.; Xu, L. Incentives for quality improvement efforts coordination in supply chains with partial cost allocation contract. Int. J. Prod. Res. 2016, 54, 6216-6231. [CrossRef]

24. Kaya, M.; Özer, Ö. Quality risk in outsourcing: Non-contractible product quality and private quality cost information. Nav. Res. Logist. 2009, 56, 669-685. [CrossRef]

25. Hung, S.J. An integrated system of activity-based quality optimization and economic incentive schemes for a global supply chain. Int. J. Prod. Res. 2011, 49, 7337-7359. [CrossRef]

26. Baake, P.; Schlippenbach, V.V. Quality distortions in vertical relations. J. Econ. 2011, 103, 149-169. [CrossRef]

27. Georgiadis, P.; Vlachos, D.; Iakovou, E. A system dynamics modeling framework for the strategic supply chain management of food chains. J. Food Eng. 2005, 70, 351-364. [CrossRef]

28. Piewthongngam, K.; Vijitnopparat, P.; Pathumnakul, S.; Chumpatong, S.; Duangjinda, M. System dynamics modelling of an integrated pig production supply chain. Biosyst. Eng. 2014, 127, 24-40. [CrossRef] 
29. Stave, K.A.; Kopainsky, B. A system dynamics approach for examining mechanisms and pathways of food supply vulnerability. J. Environ. Stud. Sci. 2015, 5, 321-336. [CrossRef]

30. Joshua, A.; Wilson Mark, M.J.; Kathryn, B.; Rich Karl, M. Identifying the precursors of vulnerability in agricultural value chains: A system dynamics approach. Int. J. Prod. Res. 2021, 59, 683-701.

31. Größler, A.; Thun, J.H.; Milling, P.M. System dynamics as a structural theory in operations management. Prod. Oper. Manag. 2008, 17, 373-384. [CrossRef]

32. Minegishi, S.; Thiel, D. System dynamics modeling and simulation of a particular food supply chain. Simul.-Pract. Theory 2000, 8, 321-339. [CrossRef]

33. Guma, I.P.; Rwashana, A.S.; Oyo, B. Household food security policy analysis: A system dynamics perspective. Int. J. Sci. Technol. Res. 2016, 5, 278-285.

34. Olafsdottir, A.H.; Gudbrandsdottir, I.; Sverdrup, H.U.; Bogason, S.G.; Olafsdottir, G.; Stefansson, G. System dynamics modelling and system analysis applied in complex research projects-the case of VALUMICS. Int. J. Food Syst. Dyn. 2018, 9, 409-418.

35. Teimoury, E.; Nedaei, H.; Ansari, S.; Sabbaghi, M. A multi-objective analysis for import quota policy making in a perishable fruit and vegetable supply chain: A system dynamics approach. Comput. Electron. Agric. 2013, 9, 37-45. [CrossRef]

36. Schneider, M. Dragon head enterprises and the state of agribusiness in China. J. Agrar. Chang. 2016, 17, 3-21. [CrossRef]

37. Fu, H.; Zhao, C.P.; Cheng, C.X.; Ma, H.Y. Blockchain-based agri-food supply chain management: Case study in China. Int. Food Agribus. Manag. Rev. 2019, 23, 667-679. [CrossRef]

38. Zhou, L.; Cao, L. The evolution and innovation of rural economic organizational forms: Investigation report on agricultural industrialization in Laiyang, Shandong, China. Econ. Res. J. 2001, 1, 83-94.

39. Yang, S.; Zhuang, J.C.; Wang, A.F. Evolutionary game of quality and safety investment of agricultural products under punishment mechanism. Chin. J. Manag. Sci. 2019, 27, 181-190.

40. MARA. Opinions of the Ministry of Agriculture and Rural Affairs on Accelerating the Promotion of Brand-Strengthening Agriculture. Available online: http://www.gov.cn/zhengce/zhengceku/2018-12/31/content_5445944.htm (accessed on 31 December 2018). (In Chinese)

41. Peng, Y.; Li, J.; Xia, H.; Qi, S.; Li, J. The effects of food safety issues released by we media on consumers' awareness and purchasing behavior: A case study in China. Food Policy 2015, 51, 44-52. [CrossRef]

42. Pang, R.Z. Food Safety Ranks Top 1 in the Health Index. Available online: http://www.chinaxiaokang.com (accessed on 26 July 2016). (In Chinese).

43. Tian, X.J. What Do You Worry about Eating? Available online: https://m.chinaxiaokang.com/wap/zhongguoxiaokangzhishu/ ndxkzs/2020nianzhongguoxiaokangzhishu/2020nianzhongguoyinshixiaokangzhishu/2020/0204/885808.html (accessed on 13 February 2020). (In Chinese).

44. Hu, K.; Ma, S.H. Research on the food safety in food supply chain with small suppliers. J. Syst. Sci. Math. Sci. 2013, 33, 892-904.

45. Forrester, J.W. Industrial Dynamics; Pegasus Communications: Waltham, MA, USA, 1961.

46. Barlas, Y. System dynamics: Systemic feedback modeling for policy analysis. Syst. Dyn. 2002, 1, 1-68.

47. Sterman, J.D. Business Dynamics: Systems Thinking and Modeling for a Complex World; McGr aw-Hill: New York, NY, USA, 2000.

48. Martín-Herŕan, G.; Taboubi, S.; Zaccour, G. On myopia in a dynamic marketing channel. Les Cah. Du GERAD 2006, 37, 1-24.

49. Alessandra, B. Advertising and price to sustain the brand value in a licensing contract. Adv. Dyn. Games 2013, 12, 377-394.

50. Ilaria, M.; Angelo, N.; Umberto, P.; Paolo, R. Understanding the purchasing behavior of consumers in response to sustainable marketing practices: An empirical analysis in the food domain. Sustainability 2021, 13, 6169. 